\title{
O Pequeno Grupo e o Paradigma da COMPleXIDAde EM Edgar Morin ${ }^{1}$
}

\author{
Míriam Cristiane Alves ${ }^{2}$ e Nedio Seminotti ${ }^{3}$
}

Faculdade de Psicologia - PUCRS

Os diferentes modos de ação e reflexão frente ao fenômeno grupo são assumidamente controvertidos. Eles esbarram na dicotomia entre indivíduo e sociedade, entre partes e todo. Conforme olhardoobservador, o indivíduo ou o grupo desaparecem, abrindo-se um intransponível abismo mental entre os fenômenos sociais e individuais. Noções sobre indivíduo e sociedade, indivíduo e grupo são vistas freqüentemente como antagônicas e concorrentes, mas, quando tomadas na perspectiva do pensamento complexo, serão entendidas como complementares. $O$ presente artigo tem por objetivo trazer ao debate teórico possibilidades de articular o paradigma da complexidade ao estudo dos pequenos grupos, utilizando-se como principal referencial o Paradigma da Complexidade em Edgar Morin. Desde que, no pensamento complexo, sujeito, pequeno grupo e contexto maior são constitutivos uns dos outros, a um só tempo, é aqui enfatizada a interferência recíproca que caracteriza uma relação dialógica, sistêmica, hologrâmica, recursiva e complexa.

Descritores: Grupo. Pequeno grupo. Dinâmica de grupo.

1 Este artigo é resultado da Dissertação de Mestrado intitulada "Produção e Organização do Sistema Pequeno Grupo 'Oficina de Capoeira': um estudo no contexto da reforma psiquiátrica”, defendida em março de 2005, na Faculdade de Psicologia - PUCRS. Foi apresentado no XVI Congreso da Federación Latinoamericana de Psicoterapia Analítica de Grupo, Guadalajara - México, 2004. Órgão Financiador: CAPES.

2 Educadora Física e Especialista em Saúde Mental Coletiva, Mestre em Psicologia Social - PUCRS. Endereço para correspondência: Av. Dante Ângelo Pilla 708. Porto Alegre, RS. CEP 91150-080. Endereço eletrônico: oba.olorioba@ gmail.com

3 Docente do Programa de Pós-Grauação em Psicologia - PUCRS, Coordenador do Grupo de Pesquisa "Processos e Organizações dos Pequenos Grupos". Endereço para correspondência: Av. Ipiranga 6681, Porto Alegre, RS. Caixa Postal 1429. CEP 90619900. Endereço eletrônico: nedios@pucrs.br 
$\mathrm{O}$ s diferentes modos de ação e reflexão frente ao fenômeno grupo são assumidamente controvertidos. Eles esbarram na dicotomia entre indivíduo e sociedade, que atravessa mais um século mantendo aceso o debate sobre a complexidade das relações entre o todo e as partes, entre indivíduo e grupo. Conforme o olhar do observador, o indivíduo desaparece no grupo, que passa a ser tomado como uma massa homogênea, onde seus elementos estão fusionados, ou são vistos sem interconexão, sublinhando as individualidades. Quando o observador fica capturado pela tensão grupal ou envolvido em sua dinâmica, os indivíduos são percebidos como expressões da grupalidade. Nestes casos, a interpretação/intervenção recai sobre o grupo como totalidade (Corrêa \& Seminotti, 2005) e, segundo esta concepção, o grupo precede os indivíduos (Zimerman, 1993). Emerge no grupo o social, algo que não é encontrado em cada indivíduo que o compõe. É nesse sentido que, segundo Durkheim, "a vida coletiva só pode existir no todo formado pela reunião dos indivíduos" (1970, p. 35) e "o fenômeno social não depende da natureza pessoal dos indivíduos" (p. 34). Autor que define o grupo social como mais do que a soma das partes e que continua tendo forte influencia na compreensão da relação indivíduo/grupo.

Em contrapartida, tem-se o paradigma em que o grupo é quem desaparece, tornando-se uma abstração, e o indivíduo passa a ser tomado como a única realidade, sendo o grupo uma expressão resultante das características de cada um. Aqui, o indivíduo precede o grupo. Para Hobbes (1651/1992), apontado como um dos interlocutores deste pensamento (Barros, 1994), a multidão é nada mais que a soma de vontades individuais que, em determinado momento, convergem, mas não chegam a formar uma unidade. O indivíduo humano, segundo este autor, não é, por natureza, social, ele é livre, desde uma perspectiva individualista, e no exercício de sua liberdade tende a viver em constante luta com o outro pela posse dos bens disponíveis. Essa situação só se resolve com um pacto de respeito às posses do outro e à delegação ao Soberano da fiscalização do cumprimento do pacto (Seminotti, 2000).

Tanto numa concepção quanto na outra há dimensões que são inabordáveis pelo pensamento, abrindo-se um intransponível abismo mental entre os fenômenos sociais e individuais (Elias, 1994). Noções que, num primeiro momento, podem ser vistas como antagônicas e concorrentes, mas que também são complementares quando tomadas na perspectiva do pensamento complexo. 


\section{O Pequeno Grupo e o Paradigma da Complexidade em Edgar Morin}

Elias (1994) chama nossa atenção para a clara ligação entre os abismos que se abrem na relação entre indivíduo e sociedade, que se expressam em nossos pensamentos e nas contradições entre as exigências sociais e as necessidades individuais, que constituem um traço permanente em nossa vida. Segundo este autor, os projetos que nos são oferecidos para o enfrentamento dessas dificuldades, muitas vezes, voltam-se para solucionar o social à custa do individual ou vice-versa. As questões que envolvem a dicotomia indivíduo/ sociedade já foram amplamente discutidas, tendo sido abordadas por diferentes autores e áreas do conhecimento (Berger \& Luckmann, 1985; Durkheim, 1970; Elias, 1994; Farr, 2000; Hobbes, 1651/1992; Matta, 1997).

Na psicologia dos Pequenos Grupos os autores discutem a relação indivíduo/grupo numa tentativa de entender a articulação entre eles. Moreno (1972), o criador do Psicodrama e da expressão "psicoterapia de grupo", apoiou-se no teatro para propor esta discussão. Lança mão da noção de indivíduo-protagonista, o qual põem em cena as questões que surgem nos contextos social, grupal e dramático. Lewin (1948) afirma que o indivíduo é função do grupo e todo comportamento dele deve ser visto como resultante da totalidade dinâmica do grupo. Para dar uma idéia do que pensa sobre isso, o autor afirma, por exemplo, que um ataque ao indivíduo é um ataque ao grupo. Em ambas as propostas, o indivíduo é representante do grupo, sem ser, a um só tempo, tratado em sua singularidade.

Outros autores no âmbito da Psicologia, porém com pressupostos psicanalíticos, dos quais destacamos Bion e Pichon-Rivière, também propuseram conceitos que permitiram compreender a relação indivíduo/grupo. Bion (1970), especialmente em sua noção de cultura de grupo, considera os conflitos existentes entre a mentalidade de grupo e os desejos individuais e sublinha que pode haver uma "mudança catastrófica", quando idéias novas promovem uma ruptura na mentalidade do grupo prevalente, para constituir uma nova. PichonRivière (1988), com sua idéia de porta-voz, indica o indivíduo que anuncia e/ou denuncia os conteúdos latentes da grupalidade. Contempla essa mesma questão, ao afirmar que é na confluência das experiências individuais e coletivas que nasce o conteúdo que será manifestado pelo porta-voz do grupo.

Agora, embora os dois últimos autores prestem atenção à relação indivíduo/grupo, eles pressupõem que há uma estrutura individual que se faz pre- 
sente perenemente. Isto é, nas relações intragrupo têm forte influência as histórias individuais primitivas de seus membros, que tendem a definir os processos grupais. Assim, a vida do grupo se inclina, segundo as interpretações destes autores, a ser uma reprodução da configuração familiar dos seus membros.

A dicotomia indivíduo/sociedade ainda atravessa a contemporaneidade, produzindo efeitos nos estudos sobre os processos grupais e trazendo à tona a problematização sobre a relação entre indivíduo/sujeito e grupo (Barros, 1994; Diegoli, 2003; Fernández, 1989; Lane, 1985; Zanella, Lessa, \& Da Ros, 2002).

Repensar essa dicotomia implica considerar suas inter-relações como "fundante de similaridades e singularidades que necessitam ser compreendidas na complexa trama que as opõem, negam, produzem, reproduzem, enfim, constituem" (Zanella et al. 2002, p. 212). Nesta perspectiva, a partir do paradigma da complexidade, do "tecer junto" proposto por Morin (2002a, 2002b, 2003), caminhamos em busca das articulações despedaçadas deste par dicotômico. O presente artigo, de natureza teórica, tem por objetivo trazer ao debate acadêmico a possibilidade de articulação do paradigma da complexidade ao estudo dos pequenos grupos.

\section{O Paradigma da Complexidade em Edgar Morin}

A ambição da complexidade é prestar contas das articulações despedaçadas pelos cortes entre disciplinas, entre categorias cognitivas e entre tipos de conhecimento (Morin, 2002a, 2002b). O paradigma da complexidade questiona/perturba o paradigma "clássico", trazendo a idéia de complexificação das relações. Os princípios de explicação "clássicos" - redução, separação e simplificação - unificam o que é múltiplo, quantificam o que é qualificável, simplificam o que é complexo. "O pensamento redutor atribui a "verdadeira' realidade não às totalidades, mas aos elementos, não às qualidades, mas às medidas, não aos seres e aos entes, mas aos enunciados formalizáveis e matematizáveis" (Morin, 2002a, p. 27). Ele reduz, separa e simplifica para tornar o objeto/sistema ${ }^{4}$ de estudo conhecível e, sobretudo, manipulável. Em

4 O termo objeto/sistema de estudo está articulado à noção de que não existe uma realidade independente de um observador (Morin, 2002a, 2002b, 2003). 


\section{O Pequeno Grupo e o Paradigma da Complexidade em Edgar Morin}

contrapartida, o pensamento complexo a um só tempo separa e associa, reduz e complexifica, trazendo a relação de convívio e inseparabilidade dos antagônicos, dos concorrentes, dos contrários, que Morin (2002a, 2003) denomina de "princípio dialógico". Ou seja, aquele que procura estabelecer a comunicação, a articulação entre diferentes lógicas, assumindo as relações paradoxais, conflitivas e de tensão entre partes e todo, indivíduo e grupo, indivíduo e sociedade, sem sacrificar um em detrimento do outro.

O pensamento complexo concebe a emergência das potencialidades criativas sem reduzi-las a unidades simplificadas ou a totalidades generalizadas, ou seja, sem reduzi-las às partes ou ao todo, mas sim, tomando-as como produções concebidas nas inter-retroações entre elas. Nesse sentido, temos a perspectiva do "princípio sistêmico" (Morin, 2002a, 2003), que liga o conhecimento das partes ao conhecimento do todo, concebendo a relação de interdependência entre eles. Na relação entre as partes e o todo, este autor resgata a idéia de que assim como as partes estão inscritas no todo, o todo também está inscrito nas partes - "princípio hologrâmico". Este princípio torna visível o aparente antagonismo entre partes e todo, entre indivíduo e sociedade, entre indivíduo e pequeno grupo. Indica-nos que não podemos compreender um sistema complexo segundo o pensamento reducionista, ou seja, compreender o todo somente a partir da separação, simplificação e redução das partes. Tampouco, podemos negligenciar as partes em detrimento de um todo homogêneo. A sociedade, por exemplo, conforme este princípio, está presente em cada indivíduo por meio da cultura, da linguagem etc, assim como cada indivíduo contém em si as características da sociedade da qual pertence.

No pensamento complexo, conhecer o sistema vivo - conceito sobre o qual vamos desenvolver ao longo do texto - não implica separá-lo do seu meio ambiente, mas contextualizá-lo nesse meio, considerando todo acontecimento e informação que o atravessa numa relação de inseparabilidade. Porém, não basta inscrever os acontecimentos e as informações em um quadro ou perspectiva como numa fotografia, por exemplo. Faz-se necessário procurar as relações e inter-retroações entre partes e todo, entre diferentes sistemas, considerando o contexto sócio-histórico onde estão situados; as relações de reciprocidade entre indivíduos e grupo, indivíduos e sociedade. Ou seja, "como uma modificação local repercute sobre o todo e como uma modificação do 
todo repercute sobre as partes" (Morin, 2003, p. 25). Portanto, a contextualização não se refere simplesmente ao espaço físico, ao meio ambiente, mas às relações entre os elementos envolvidos (Vasconcellos, 2003) e entre elementos e acontecimentos a um só tempo.

As noções de elemento e acontecimento estão intrinsecamente relacionadas - "todo elemento pode ser considerado acontecimento na medida em que o consideramos situado na irreversibilidade temporal, uma manifestação ou atualização, isto é, em função de seu aparecimento e desaparecimento, como em função de sua singularidade" (Morin, 2002a, p. 251). Desde o ponto de vista da Física, Prigogine (2003) indica que a noção de acontecimento implica na idéia de que uma situação pode ou não ocorrer, sendo sempre uma contingência. Assim, introduz a incerteza na previsão do futuro, demonstrando o caráter não determinista da história humana: "O acontecimento mais insignificante pode mudar o curso da história” (Prigogine, 1996, p. 26). Por sua vez, para Morin (2002a), a noção de acontecimento é complexa por remeter a outras noções como o aleatório, o improvável, o acidental, o singular, o concreto, o histórico. Portanto, não pode ser entendido como uma produção pensável a partir da lógica e da estatística, como no caso do elemento, mas, ao contrário, ele possui um caráter singular e fenomenal. Ele é conflito, crise, acidente, contingência, podendo transformar, modificar, destruir, desenvolver a partir de encontros, interações, organizações. Nessa compreensão, a noção de acontecimento é relativa, de modo que o mesmo fenômeno pode ser elemento em um sistema e acontecimento em outro (Morin, 2002a).

A mudança catastrófica proposta por Bion (1970) sugere essa noção de acontecimento. Para ele, uma idéia nova pode produzir uma ruptura na mentalidade do grupo, mudando seu curso. Porém, esta proposta, como todas as outras deste autor, está fundada na interpretação psicanalítica das vivências infantis individuais, enquanto que, a partir de Morin, podemos ampliar essa compreensão, na medida em que as mudanças no sistema grupo não estão ligadas exclusivamente às vivências infantis, numa perspectiva individual e determinista. Ou seja, temos uma rede de relações que pode provocar um acontecimento e a mudança no curso do sistema grupo.

Pensar o objeto/sistema de estudo contextualizado implica em sistemas complexos, cujas múltiplas inter-retroações não se inscrevem numa 


\section{O Pequeno Grupo e o Paradigma da Complexidade em Edgar Morin}

causalidade linear, mas em relações causais retroativas e recursivas (Morin, 2002a, 2003). Assim, esse autor desenvolve a idéia do "princípio do circuito retroativo" e do "princípio do circuito recursivo". O primeiro refere-se aos processos "auto-reguladores" (Morin, 2002b, 2003) e relaciona-se com a noção de feedback, de retroalimentação, na qual "uma parte do efeito (output) ou do resultado do comportamento/funcionamento do sistema volta à entrada do sistema como informação (input) e vai influir sobre o seu comportamento subseqüente" (Vasconcellos, 2003, p. 115). Já o princípio do circuito recursivo ultrapassa a idéia de regulação, avançando para a de autoprodução e auto-organização (Morin, 1996, 2002a, 2002b, 2003). É um circuito que pode ser representado graficamente pela espiral, cujos produtos e efeitos são, eles próprios, produtores e causadores daquilo que os produz. Os indivíduos humanos, por exemplo, produzem a sociedade nas e pelas inter-relações, e a emergência da sociedade produz a humanidade dos mesmos, fornecendo-lhes a linguagem e a cultura (Morin, 1996, 2003).

Segundo Morin (1996, 2002a, 2003), os seres vivos, os humanos e as sociedades são auto-organizadores e não param de se autoproduzirem. Eles possuem uma autonomia que se fundamenta na dependência do meio ambiente e, nesse sentido, os sistemas vivos, humanos e sociais precisam ser concebidos como auto-ecoorganizadores. Eis o "princípio da autonomia/dependência" ou "auto-organização" proposto por este autor, que torna o conceito de autonomia complementar ao de dependência e, ao mesmo tempo, antagônico. Autonomia que se constrói em termos relacionais e relativos, distanciando-se, portanto, de uma liberdade absoluta emancipada de qualquer dependência. A autonomia do indivíduo/sujeito, sendo dependente do ambiente onde vive, depende de sua ascendência genética e da sociedade em que se inscreve (Morin, 1996, 2002a, 2003).

A noção de sujeito em Morin (1996, 2003) parte de uma base bio-lógica, correspondendo à lógica própria do ser vivo. Refere-se a um sujeito que depende do meio biológico, social e cultural para tornar-se autônomo - sujeito autoecoorganizado. Noção de sujeito que se constrói a partir da noção de indivíduo - este que, do ponto de vista biológico, é produto de um ciclo de reprodução e reprodutor em seu ciclo. Todavia, para chegar-se à noção de sujeito, esta organização biológica necessita de uma dimensão cognitiva/computacional como 
indispensável à vida. A computação é o tratamento de estímulos, de informações, de signos, de símbolos e de mensagens que permite ao indivíduo agir dentro do universo exterior, assim como de seu universo interior, e reconhecêlos. Sujeito que computa por conta própria, por si mesmo e para si mesmo. Eis a idéia de cômputo, que é o ato pelo qual o sujeito se constitui, colocando-se no centro de seu mundo (egocentrismo) para lidar com ele, considerá-lo, preservarse, proteger-se etc. "A noção de sujeito está indissoluvelmente unida a esse ato, no qual não só se é a própria finalidade de si mesmo, mas em que também se é autoconstitutivo da própria identidade" (Morin, 1996, p. 49). A identidade do sujeito comporta um princípio de distinção, de diferenciação e de reunificação, o que lhe possibilita a capacidade de referir-se ao mesmo tempo a "si" (auto-referência) e ao mundo exterior (exo-referência). Ou seja, para referir-se a si mesmo, é preciso referir-se ao mundo externo - processo de auto-exo-referência. Processo que é constitutivo da identidade subjetiva, permitindo que se opere a distinção entre "si" e "não-si", "mim" e "não-mim", "eu” e outros "eus".

A realidade do sujeito mostra-se mais complexa, à medida que ele se torna, ao mesmo tempo, egocêntrico, genocêntrico - dedicado à produção e defesa da progenitura - e sociocêntrico. É preciso conceber o sujeito como aquele que dá unidade e invariância a uma pluralidade de personagens, de caracteres, de potencialidades, podendo oscilar entre o egocentrismo e a devoção absoluta (Morin, 1996, 2002a, 2002b, 2003).

O sujeito possui um caráter existencial "porque é inseparável do indivíduo, que vive de maneira incerta, aleatória, e acha-se, do nascimento à morte, em um meio ambiente incerto, muitas vezes ameaçador e hostil" (Morin, 2003, p. 124). Ele "não é uma essência, não é uma substância, mas não é uma ilusão” (Morin, 2003, p. 128). O sujeito é único e a individualidade não é apenas diferença e singularidade, mas também subjetividade.

A subjetividade, no presente estudo, é compreendida como um vir-a-ser aleatório produzido em uma rede de sistemas interdependentes, na trama de inter-relações, de grupos sociais, culturais e biológicos. Uma subjetividade que não é o ser, tampouco a essência, a raiz do ser, mas sim, os modos de ser na auto-eco-organização, na interação consigo, com o outro, com o sistema social. Portanto, a subjetividade é compreendida como uma emergência produzida na inter-relação entre o social, o cultural e o biológico; uma experiência 
fenomenal, individual e coletiva a um só tempo, pressupondo a autonomia e a dependência na interação com o outro para a produção de sujeitos.

Nessa concepção, os sujeitos se constituem mutuamente em inter-relação no e como o pequeno grupo e o grupo social. Eles produzem movimentos de constituição de si e do outro, no contexto das relações sociais, marcados por suas histórias de vida e pelos lugares sociais que ocupam na complexa trama em que se envolvem. "Ao mesmo tempo, essas histórias e lugares são constantemente transformados, o que caracteriza essa relação com diálogo permanente marcado por movimentos nem sempre harmônicos" (Zanella et al. 2002, p. 213).

\section{O Sistema Pequeno Grupo e suas Relações Complexas}

A noção de pequeno grupo, apresentada no presente estudo, acompanha a conceituação dos teóricos grupalistas que consideram como característica importante o fato de que, nele, é propiciado aos indivíduos/sujeitos que todos se vejam e se ouçam simultaneamente, conheçam-se e reconheçam-se em suas singularidades e diversidades, devido ao número reduzido de participantes (Anzieu, 1993; Caparróz, 1998; Seminotti, 2000; Zimerman, 1993). Significa dizer que, segundo este critério, mais importante do que o número de pessoas é o modo em que se organizam para se ver e se ouvir. Noção que, no presente estudo, é vista e desenvolvida a partir do pensamento complexo, ou seja, dos princípios do circuito retroativo e recursivo, sistêmico, dialógico, hologrâmico e de auto-organização.

Segundo Morin (2002a, 2002b), o sistema é uma unidade e multiplicidade a um só tempo, ou seja, unidade múltipla. Nessa proposta, o sistema pequeno grupo é uma unidade constituída pelos indivíduos/sujeitos e seus subgrupos e as inter-relações produzidas entre eles, além da relação entre esse sistema e o contexto sócio-histórico do qual faz parte.

Nas palavras de Morin (2002a), o sistema é o que "exprime a unidade complexa e o caráter fenomenal do todo, assim como o complexo das relações entre o todo e as partes" (2002a, p. 265). O sistema se constitui não pela existência dos elementos, das partes, dos sujeitos e dos acontecimentos, mas fun- 
damentalmente pelas inter-relações entre eles. Dito de outro modo, o importante não é o número de elementos de um conjunto - tal como num sistema mecânico, no qual mais importante do que as relações são as partes/peças -, mas as interrelações nele estabelecidas, que, por sua vez, constituirão uma unidade global. Todavia, para Morin (2002a, 2002b), estas duas características da definição de sistema, ou seja, a inter-relação e a unidade global, precisam ser ligadas pela idéia de organização: assim que adquirem um caráter regular, as inter-relações entre elementos, sujeitos e acontecimentos se tornam organizacionais.

Podemos dialogar, aqui, com Capra que discute os sistemas, principalmente, do ponto de vista das ciências exatas. Segundo Capra (1996), os sistemas vivos são totalidades integradas cujas propriedades do todo não podem ser reduzidas às das partes e, conforme Morin (2002a, 2002b), as propriedades das partes também não podem ser reduzidas às do todo. As propriedades do todo emergem das "relações de organização" das partes, ou seja, nascem de uma configuração de relações ordenadas que é característica desse sistema; propriedades sistêmicas que "são destruídas quando um sistema é dissecado em elementos isolados" (Capra, 1996, p. 46).

Observar o pequeno grupo como um sistema vivo implica considerar, assim como nos refere Capra (2002), que os sistemas sociais envolvem não apenas seres humanos vivos, como também a linguagem, a consciência e a cultura. Nessa compreensão, torna-se evidente que sejam sistemas cognitivos e, deste modo, "parece estranho pensar que não sejam vivos" (p. 94). O autor sugere ainda que "uma organização humana só será um sistema vivo se for organizada em rede ou contiver redes menores dentro dos seus limites" (p. 117).

Nesta perspectiva, compreendemos o sistema pequeno grupo enquanto um sistema vivo formado por indivíduos/sujeitos humanos possuidores de linguagem, cultura e consciência. Atividades humanas que são fundantes no processo de produção e organização grupal.

A cultura constitui o meio no qual o sujeito humano é produzido que, por sua vez, recursivamente, produz a própria cultura. Ela é o meio no qual o sujeito se transforma no curso de sua história de vida. No pequeno grupo, sua cultura resulta em ações, inter-relações e recursões que implicam uma organização que, por sua vez, contribui para a definição de sua característica, singularidade e identidade. 


\section{O Pequeno Grupo e o Paradigma da Complexidade em Edgar Morin}

A consciência, segundo Morin (2003), é a emergência última da qualidade do sujeito - "é a emergência reflexiva, que permite o retorno da mente a si mesmo, em circuito" (p. 126).

A linguagem, conforme Maturana (2001), é o que diferencia os seres humanos de outros sistemas vivos. Para este autor, o linguajar é o modo de existir dos seres humanos - tudo o que fazem o fazem na linguagem.

Segundo esta concepção, são muitos os elos que se interconectam para a produção e organização do sistema pequeno grupo. Além deles, não podemos deixar de considerar os processos de inter-relação, de organização e desorganização, subjetivação e sujeição, caos e ordem entre partes e todo, indivíduo/sujeitos, pequeno grupo e sistema maior. Processos que retroagem sobre o todo e as partes, gerando aumento e/ou inibição das potencialidades individuais e coletivas que, por sua vez, produzem novos processos. Sistema pequeno grupo, haja vista a configuração de inter-relações e recursões que o constitui.

Conforme Morin (2002a, 2002b), um conjunto de interações constitui uma organização. Esta é o encadeamento de relações entre elementos, entre partes, que produz um sistema dotado de qualidades desconhecidas quanto aos elementos, tomados isoladamente (Morin, 2002a, 2002b). A organização liga de modo inter-relacional as partes, os elementos diversos que se tornam elementos de um todo. Ela também "assegura solidariedade e solidez relativa a estas ligações, assegurando então ao sistema certa possibilidade de duração apesar das pertubações aleatórias" (Morin, 2002a, p. 133). E permite regular, dar coerência e sentido às ações e inter-relações produzidas no sistema - ela produz, transforma, liga e mantém (Morin, 2002a, 2002b).

No sistema pequeno grupo, as inter-relações são motivadas pelas singularidades e diversidades dos sujeitos, pelo próprio sistema grupo e seus subgrupos e pelas relações produzidas, gerando processos de organização e desorganização, de subjetivação e sujeição, de ordem e caos. A organização resulta na ligação dos indivíduos/sujeitos que constituem o sistema, confirma a interdependência entre eles, define uma relação de compromisso com normas, valores e objetivos comuns, produz e mantém a singularidade e a identidade do sistema pequeno grupo. 
Morin (2002a) concebe a organização "como reorganização permanente de um sistema que tende a se desorganizar", "como reorganização permanente de si, isto é, não apenas organização, mas auto-reorganização" (p. 266). Organização que cria ordem e desordem, ou seja, cria ordem, criando seu próprio determinismo sistêmico que pode ser flexível, comportar suas zonas de aleatoriedade, ao mesmo tempo em que cria desordem, produzindo degradação e degenerescência. Para este autor, a organização é ativa, ou seja, comporta armazenamento, repartição e controle da energia, ao mesmo tempo em que, por seu trabalho, comporta gasto e dispersão de energia. Portanto, organização, ordem e desordem se implicam mutuamente. A organização em Morin (2002a) é uma noção circular que, remetendo ao sistema, remete a si mesmo; ela é constitutiva de relações, formações, transformações, invariâncias e regularidades, que circularmente a constituem.

Tomando essa noção de organização, apontamos para o estabelecimento e emergência dos organizadores grupais no sistema pequeno grupo, ou seja, elementos que potencializam e/ou inibem as interações, socializações e articulações entre diferentes sujeitos e entre estes, o pequeno grupo e o contexto maior.

Desde a perspectiva da psicologia dos grupos, alguns autores (Anzieu, 1993; Kaës, 1995) propuseram organizadores do processo de grupo baseados nas concepções de Spitz (1972), em termos das fantasias individuais e originárias, representações, organizadores socioculturais etc. Tais organizadores foram considerados por Seminotti (2001), que a eles acrescentou os subgrupos e as relações intra e inter-subgrupos. Moreno (1972), Bion (1970) e PichonRivière (1988), entre outros autores, propuseram, respectivamente, conceitos para compreender o processo do grupo, tais como as cenas, a mentalidade de grupo e a tarefa, que, do nosso ponto de vista, também são organizadores do processo grupal. Esses, desde a perspectiva do método de pesquisa em grupo, constituem uma estratégia que permite observar, descrever e analisar o processo ou a vida imaterial do mesmo (Seminotti, 2006).

Alguns elementos da complexidade, tais como, instabilidade, ordem e caos, também são por nós compreendidos como organizadores grupais. Segundo Diegoli (2003), a instabilidade permite o desenvolvimento do potencial criativo no pequeno grupo e, onde há muito controle, não há criatividade. A instabilidade é capaz de criar oportunidades de movimento no sistema, gerando novas formas de comportamento. Ela é capaz de criar oportunidades de ações, inter-relações e 


\section{O Pequeno Grupo e o Paradigma da Complexidade em Edgar Morin}

recursões no sistema pequeno grupo, produzindo novos modos de os sujeitos se relacionarem, subjetivando-os, produzindo modos de existência.

Numa tentativa de categorizar os organizadores grupais, Seminotti, Borges e Cruz (2004) os classificaram em formais e informais. Os formais são aqueles que são levados ao sistema pequeno grupo como algo predeterminado e que deve ser obedecido por seus participantes. São as consignações específicas como as tarefas a serem cumpridas, as exigências organizacionais, institucionais ou sociais como, por exemplo, o enquadre, a coordenação e a tarefa. Quanto aos informais, são qualidades emergentes produzidas no próprio sistema pequeno grupo, ou seja, que os participantes do grupo constroem no processo histórico do mesmo, como as lideranças e as tarefas emergentes, a tarefa implícita, os novos papéis e o intercâmbio entre eles, que dialogam com os formais e constroem a singularidade do sistema, revelando o que o caracteriza e o diferencia do entorno.

Essa singularidade do grupo, produzida na relação entre organizadores formais e informais, constitui um ente imaterial, intangível e reconhecido apenas pela intuição dos indivíduos/sujeitos que pertencem a ele e que reconhecem sua influência em seus modos de ser. Além disso, ele se constitui enquanto um organizador grupal e pode ser reconhecido como a ideologia Bauleo (1974), o clima do grupo Lewin (1948), a representação do grupo Anzieu (1993), a mentalidade do grupo Bion (1970) ou a noosfera Morin (2002b). Neste caso, os sujeitos também são produtos e produtores dessa entidade abstrata que, por sua vez, pode inibir ou potencializar a vida do sistema pequeno grupo e de cada sujeito.

Seminotti (2001) sublinha que, ao contrário do que se lê na maioria dos textos sobre grupos, os quais ressaltam-no como dispositivo que fomenta as potências individuais, às vezes, os organizadores e a organização do pequeno grupo constrangem afetiva e ideologicamente de maneira significativa os seus participantes. Nesta compreensão, saímos de uma noção de um ideal de grupo ainda muito presente nos estudos sobre os pequenos grupos.

Na tradição lewiniana, por exemplo, ele é considerado como uma estrutura coesa que congrega relações sociais coerentes e regulares e, por tal razão, pode ser multiplicador de mudanças de comportamento (Lewin, 1948). Já nas publicações de Lane (1985), o grupo aparece como condição de libertação dos sujeitos a partir da produção coletiva, desde uma perspectiva do processo histórico. 
Considerando a complexidade, esse ideal de grupo fica colocado em discussão, na medida em que o todo do pequeno grupo é, ao mesmo tempo, mais e menos do que a soma de suas partes: menos, quando uma organização provoca coações que inibem as potencialidades existentes em cada parte e mais, quando o todo organizado produz qualidades emergentes que, anteriormente, não existiam, que retroagem ao nível das partes e podem estimulá-las a exprimir suas potencialidades (Morin, 2002a, 2003). E, considerando a retroação da criação dos sujeitos sobre o sistema pequeno grupo, pode-se dizer que o todo desse sistema passa a ser mais do que seu próprio todo. Ou seja, "o todo enquanto todo retroage sobre as partes, que, por sua vez, retroagem sobre o todo". Portanto, "o todo é mais do que uma realidade global, é um dinamismo organizacional" (Morin, 2002a, p. 261).

A idéia de recorrência organizacional, proposta por Morin (2002a), é necessária para chegarmos à autoprodução e à auto-organização que permitem compreender os processos de subjetivação e de sujeição. Ou seja, a produção de modos de existência, de modos pelos quais os sujeitos se auto-experimentam, autoproduzem e auto-organizam nas inter-retroações entre partes e todo, entre sujeitos, pequeno grupo e sistema maior.

Morin (2002a) aponta para a necessidade de evitarmos toda definição de autos que faça desaparecer um dos dois aspectos da vida, seja o generativo, seja o fenomenal. Nesse sentido, também aponta para a necessidade "de uma concepção complexa, que revele a unidade dessa dualidade e a dualidade dessa unidade", ou seja, "unidualidade dentro da auto-organização", "dupla organização que é una em seu caráter recorrente" (p. 315). Nesta perspectiva, a conjunção da organização generativa e da organização fenomenal constitui a auto-organização (Morin, 2002a). Enquanto a organização generativa constitui a regeneração, a reorganização permanente e a reprodução periódica do sistema vivo, a organização fenomenal constitui a praxis do viver, da organização das trocas e do comportamento do sistema vivo no meio ambiente. Este autor considera o autos uma propriedade que faz com que um sistema vivo extraia de si mesmo a fonte de sua autonomia, sendo, ao mesmo tempo, dependente de energia e informação do meio ambiente. No primeiro caso, trata-se da relação intra-grupo e, no outro, do pequeno grupo com o meio ambiente. 


\section{O Pequeno Grupo e o Paradigma da Complexidade em Edgar Morin}

Assim, um sistema vivo é, a um só tempo, aberto e fechado (Morin, 2002a, 2002b, 2003). Aberto, pois necessita de informações novas do meio ambiente para continuar seu processo de amadurecimento, de crescimento e de desenvolvimento, enquanto unidade e multiplicidade. E fechado, pois necessita preservar sua identidade, singularidade e originalidade, seu modo de viver (Morin, 2002a, 2002b, 2003). Entendemos que há uma relação de antagonismo, de concorrência e de complementaridade entre estas duas noções: sistema aberto e fechado a um só tempo. "Um sistema aberto é aberto para se fechar outra vez, mas é fechado para se abrir e se fecha novamente se abrindo. $\mathrm{O}$ fechamento de um ‘sistema aberto’ é o fechamento em si” (Morin, 2002b, p. 170). Não há a exclusão da abertura do sistema vivo em detrimento de seu fechamento ou viceversa. Esta compreensão de sistema vivo, como sendo ao mesmo tempo aberto e fechado, contempla um aparente antagonismo entre as noções de autonomia e de dependência do sistema em relação ao meio ambiente.

O sistema vivo - lembremos que estamos entendendo o pequeno grupo como sistema - e o próprio sujeito humano são sistemas autônomos que percebem sua identidade e singularidade por meio das fronteiras que são abertas e os conectam com o meio ambiente ao qual pertencem. E, ao mesmo tempo, são sistemas dependentes deste meio com o qual produzem processos de troca, renovação e transformação (Morin, 2002a, 2002b). A fronteira é o que fecha e o que abre o sistema, proibindo e autorizando a passagem de informação e energia (Morin, 2002b). Embora intangível, o sistema pequeno grupo também identifica sua singularidade, sua identidade, por meio das fronteiras que são abertas e o conecta com o sistema maior do qual faz parte. Fronteiras que definem o que lhe é próprio e o que não o é. A partir delas, o sistema pequeno grupo estabelece, quando se abre, troca, renovação e transformação na interrelação com outros sistemas vivos. E quando se fecha, define assertivamente o que é seu e dos outros.

Nesta perspectiva, a auto-organização que se produz no processo de interconexão, de inter-relação com o meio ambiente por meio de um sistema vivo, ao mesmo tempo aberto e fechado, é, de fato, auto-ecoorganização (Morin, 1996, 2002a, 2003). O princípio de auto-ecoorganização é específico para os humanos e para as sociedades, haja vista que os humanos desenvolvem sua autonomia na dependência de sua cultura e as sociedades se desenvolvem na 
dependência de seu meio geológico (Morin, 2003). Portanto, compreendemos o sistema pequeno grupo como um sistema vivo produzido a partir de processos de auto-ecoorganização.

Sistema pequeno grupo, com potencial de auto-organização, que possui, assim, uma identidade própria mantida por meio de trocas constantes com o ambiente e com os próprios sujeitos do grupo, dos quais recebe a informação necessária para o desenvolvimento de seus processos internos. Deste modo, entendemos que a identidade desse sistema, aquilo que o define como singular, não é uma característica intrínseca a ele, mas uma produção mediante ações, inter-relações e recursões entre as partes e o todo do sistema, e entre este e o meio do qual faz parte. Portanto, a identidade pode ser compreendida como um fenômeno sistêmico.

Não obstante, falamos de um sistema pequeno grupo que não cria apenas uma identidade grupal para os diferentes sujeitos, mas que também permite a problematização e o reconhecimento das diferenças nas inter-relações, articulações, socializações e interlocuções entre os sujeitos do sistema pequeno grupo e o sistema social. Segundo Morin (2002a), os sistemas sociais, assim como os atômicos e biológicos, revelam que "um sistema não é só uma constituição de unidade a partir da diversidade, mas também uma constituição de diversidade (interna) a partir da unidade" (2002a, p. 260). As sociedades não produzem apenas uma cultura-identidade comum para sujeitos diversos, mas também permitem o desenvolvimento das diferenças por meio da cultura, de símbolos e de mitos.

Sistema pequeno grupo que é produzido numa rede de sistemas interdependentes, que constrói redes de relações que subjetivam e sujeitam, organizam e desorganizam. Relações que permitem a coexistência de noções antagônicas, concorrentes e complementares sobre um determinado tema ou uma dada situação, sem que haja a necessidade de exclusão de uma em detrimento da outra.

Indivíduo e sociedade, indivíduo e grupo, partes e todo, cada um deles não pode ser visto isoladamente, mas sim, numa relação de interdependência, produzindo-se, ao mesmo tempo, na transversalidade de diferentes lógicas. Eis um olhar complexo frente ao pequeno grupo, que busca elos entre indivíduo e grupo, partes e todo. Há uma contundente indissociabilidade desse par de opostos: grupo que produz sujeitos, que, por sua vez, produzem o grupo. 


\section{O Pequeno Grupo e o Paradigma da Complexidade em Edgar Morin}

$\mathrm{Na}$ perspectiva do pensamento complexo, sujeito, pequeno grupo e contexto maior são constitutivos uns dos outros a um só tempo, produzindo-se mutuamente, pois cada um abre-se ao outro. Esta interferência recíproca caracteriza uma relação dialógica, sistêmica, hologrâmica e complexa, onde sujeito, pequeno grupo e sociedade constroem aberturas para além dos próprios limites da compreensão humana, onde nos deparamos com a incompletude, com a instabilidade, com a incerteza, com o caos e com o complexo.

\section{Considerações Finais}

Um aspecto relevante a ser considerado sobre a proposta sistema pequeno grupo se refere à aplicação de conceitos como sistema vivo e auto-organização aos fenômenos sociais, em especial ao pequeno grupo. Convém considerar que estes conceitos foram formulados com base em observações/investigações sobre organismos, em especial moleculares e celulares. Sistemas vivos que, segundo Diegoli (2003), são identificados como unidades na dimensão de referência de seus componentes internos, como, por exemplo, a dimensão da Física e da Biologia ${ }^{5}$. Ou seja, segundo a autora, fisicamente a célula está definida como uma unidade autônoma, haja vista a existência de um perímetro membranoso. O ser humano pode ser identificado como unidade auto-organizada na dimensão da Biologia, considerando-se, por exemplo, seus processos celulares. No entanto, os processos psíquicos, cognitivos, de subjetividade, de consciência, assim como a vida coletiva, escapam a esta dimensão. Portanto, assim como entendemos o ser humano como multidimensional, a sentença também é válida para o pequeno grupo. E, nesse sentido, em ambas a situações, o todo não pode ser reduzido a uma parte, isto é, a uma dimensão.

Portanto, para a análise do processo grupal, devemos buscar diferentes dimensões do sistema pequeno grupo e, a um só tempo, realizar movimentos de classificação e associação, disjunção e complexificação, para dar conta do fenômeno observado. E, ainda assim, o paradigma da complexidade pressupõe a incerteza e a incompletude do conhecimento. Afinal, a história de vida do sistema pequeno grupo se constitui na articulação entre acontecimentos e necessidades grupais e individuais.

5 Para uma discussão mais ampla sobre sistemas vivos e sociais, veja-se Giddens (2000). 
Seminotti, N. A., \& Alves, M. C. (2006). The small group and the complexity paradigm in Edgar Morin. Psicologia USP, 17(2), 113133.

\begin{abstract}
The different ways of action and reflection facing group phenomenon are well known as controversial. They run against in the dichotomy between the subject and the society, between the parts and the whole. According to the view of the observer either the subject or the group disappears. This fact alone opens a mental abyss impossible to cross over in terms of social and individual phenomena. Conceptions of subject and society, subject and group that might be seen as antagonistic and concurrent, at first sight, might be taken as supplementary under the perspective of complex thinking. This theoretical article aims to bring into discussion the possibility of articulating complexity paradigm by studying small groups. The main theoretical reference is The Complexity Theory in Edgar Morin. In complex thinking, subject, small group and larger context constitute themselves at the same time. The reciprocal interference that characterizes a dialogic, systemic, hologramic, resourceful and complex relation is highlighted.
\end{abstract}

Index terms: Group. Small group. Group's dynamics.

Seminotti, N. A., \& Alves, M. C. (2006). Le petit groupe et le paradigme de la compléxité d' Edgar Morin. Psicologia USP, 17(2), 113-133.

Résumé: Les différentes façons d'action et de réflexion devant le phénomène groupe sont tout à fait polémiques à cause de la dichotomie entre l'individu et la société, entre les parties et le tout. Selon le regard de l'observateur, soit l'individu, soit le groupe disparait, en ouvrant un intransposable abîme mental entre les phénomènes sociaux et individuels. Des notions sur l'individu et la société, l'individu et le groupe, dans un premier moment, peuvent être vues comme antagonistes et concourrentes, mais elles sont aussi complémentaires si prises sous la perspective de la pensée complèxe. Cet article théorique a comme but mettre en relief dans le débat académique la possibilité d'articulation du paradigme de la compléxité pour l'étude des petits groupes. Comme principale référence, nous utilisons le Paradigme de la Compléxité d' Edgar Morin. Dans la 


\section{O Pequeno Grupo e o Paradigma da Complexidade em Edgar Morin}

pensée complèxe, le sujet, le petit groupe et le contexte plus grand font partie à la fois de la constituition l'un de l'autre. L'interférence réciproque qui caractérise une rélation dialogique, systémique, hologrammique, récursive et complèxe ici mise en évidence.

Mots-clés: Groupe. Petit groupe. Dynamique de groupe.

\section{Referências}

Anzieu, D. (1993). El grupo y el inconsciente: lo imaginário grupal. São Paulo: Casa do Psicólogo.

Barros, R. D. B de. (1994). Grupo: a afirmação de um simulacro. Tese de Doutorado em Psicologia Clínica, Faculdade de Psicologia, Pontifícia Universidade Católica de São Paulo, São Paulo.

Bauleo, A. (1974). Ideologia, grupo y família. México: Fólios.

Berger, P. L., \& Luckmann, T. (1985). A construção social da realidade. Petrópolis, RJ: Vozes.

Bion, W. R. (1970). Experiências com grupos: os fundamentos da psicoterapia de grupo. Rio de Janeiro: Imago.

Caparróz, N. (1998). Del narcisismo: aportaciones teóricas y clínicas. Madrid: Biblioteca Nueva.

Capra, F. (1996). A teia da vida. São Paulo: Cultrix.

Capra, F. (2002). As conexões ocultas. São Paulo: Cultrix.

Corrêa, J., \& Seminotti, N. (2005). Contratransferência do psicólogo coordenador de grupos. Psicologia Clínica, 17(2), 141-155.

Diegoli, S. (2003). El comportamiento de los grupos pequeños de trabajo bajo la perspectiva de la complejidad: modelos descritivos y estudio de casos. Tese de Doutorado, Faculdad de Psicologia, Universitat de Barcelona, Barcelona.

Durkheim, E. (1970). Sociologia e filosofia. Rio de Janeiro: Forense.

Elias, N. (1994). A sociedade dos indivíduos. Rio de janeiro: Jorge Zahar.

Farr, R. (2000). As raízes da psicologia social moderna. Petrópolis, RJ: Vozes.

Fernández, A. M. (1989). El campo grupal: notas para uma genealogia. Buenos Aires: Nueva Visión.

Giddens, A. (2000). Em defesa da sociología. São Paulo: Ed. UNESP. 


\section{Míriam Cristiane Alves e Nedio Seminotti}

Hobbes, T. (1992). Leviatán: la materia, forma y poder de un Estado eclesiástico y civil. Madrid: Alianza. (Trabalho original publicado em 1651)

Kaës, R. (1995). El grupo y el sujeto del grupo: elementos para uma teoria psicoanalítica del grupo. Buenos Aires: Amorrortu.

Lane, S. T. M. (1985). O processo grupal. In S. Lane \& W. Codo (Orgs.), Psicologia social: o homem em movimento (pp. 78-98). São Paulo: Brasiliense.

Lewin, K. (1948). Problemas de dinâmica de grupo (3a ed.). São Paulo: Cultrix.

Matta, R da. (1997). A casa e a rua (5a ed.) Rio de Janeiro: Rocco.

Maturana, H. (2001). Cognição, ciência e vida cotidiana. Belo Horizonte: Ed. UFMG.

Moreno, J. L. (1972). Psicodrama (2a ed.). Buenos Aires: Hormé.

Morin, E. (1996). A noção de sujeito. In D. F. Schnitman (Org.), Novos paradigmas, cultura e subjetividade (pp. 45-58). Porto Alegre: Artes Médicas.

Morin, E. (2002a). Ciência com consciência (6a ed.) Rio de Janeiro: Bertrand Brasil.

Morin, E. (2002b). O método. Porto Alegre: Sulina.

Morin, E. (2003). A cabeça bem feita: repensar a reforma, reformar o pensamento. Rio de Janeiro: Bertrand Brasil.

Pichon-Rivière, E. (1988). O processo grupal (3a ed.). São Paulo: Martins Fontes.

Prigogine, I. (2003). Criatividade da natureza, criatividade humana. In E. A. Carvalho \& T. Mendonça (Orgs.), Ensaios de complexidade 2. Porto Alegre: Sulina.

Prigogine, I. (1996). O fim da ciência? In D. F. Schnitman (Org.), Novos paradigmas, cultura e subjetividade (pp. 45-58). Porto Alegre: Artes Médicas.

Seminotti, N. (2000). La organización y dinámica del grupo psicológico: la multiplicidad/ diversidad de organizadores del grupo. Tese de Doutorado, Universidad Antónoma de Madrid, Madrid.

Seminotti, N. (2001). O grupo como ambiente de fomento e enterro dos sonhos [CD]. In Anais do Encontro da Associação Brasileira de Psicologia Social: 11. Florianópolis: ABRAPSO.

Seminotti, N., Londero, J., \& Borges, B. (2004). O grupo como organizador do ambiente de aprendizagem. Revista Psico USF, 9(2), 181-189.

Seminotti, N. (2006). Groups: What are the challenges in research. In Proceedings of the International Congress of Group Psychoterapy: 16(p. 27). São Paulo, Brazil.

Spitz, R. (1972). El primer anõ del niño: genesis de las primeras relaciones objetales (3a 
ed.). Madrid: Aguilar.

Vasconcellos, M. J. E. de. (2003). Pensamento sistêmico: o novo paradigma da ciência. Campinas, SP: Papirus.

Zanella, A. V., Lessa, C. T., \& Da Ros, S. Z. (2002). Contextos grupais e sujeitos em relação: contribuições às reflexões sobre grupos sociais. Psicologia Reflexão e Crítica, 15(1), 211-218.

Zimerman, D. E. (1993). Fundamentos básicos das grupoterapias. Porto Alegre: Artes Médicas.

Zimerman, D. E., \& Osorio, L. (1997). Como trabalhamos com grupos. Porto Alegre: Artes Médicas.

Recebido em: 5.09.2005

Revisto e encaminhado em: 26.06.2006

Aceito em: 10.07.2006 